Acta Poetica 27 (1)

PRIMAVERA

2006

\title{
Identidad y alteridad en Bajtín
}

\author{
José Alejos García
}

El tema de la identidad es un tópico del debate académico y político en la actualidad mundial. El propósito de este artículo es examinar el concepto a la luz del pensamiento filosófico de M. Bajtín, en especial el papel que la alteridad desempeña en la construcción del sujeto social.

Identity has become a worldwide issue of academic and political debate. This article aims to examine the concept in the light of M. Bakhtin's philosophical thinking, particularly considering the role otherness plays in the construction of the social subject. 



\title{
José Alejos García
}

Universidad Nacional Autónoma de México

\section{Identidad y alteridad en Bajtín}

\begin{abstract}
Este ensayo lo escribo pensando en honrar la memoria de Pierrette Malcuzynski, extrañada amiga a quien me une el interés por la actualidad del pensamiento de Bajtín.
\end{abstract}

En la vida yo participo en lo cotidiano, en las costumbres, en la nación, el Estado, la humanidad, el mundo de Dios; es allí donde yo vivo valorativamente en el otro y para otros, donde estoy revestido valorativamente de la carne del otro.

Yo me conozco y llego a ser yo mismo sólo al manifestarme para el otro, a través del otro y con la ayuda del otro. Los actos más importantes que constituyen la autoconciencia se determinan por la relación con la otra conciencia.

Mijaíl Bajtín

La búsqueda de esencias, de núcleos duros que contengan los elementos constitutivos del ser ha sido un eje de la doctrina positivista que ha influido fuertemente en el concepto de identidad, particularmente en antropología. Sus secuelas se dejan sentir en el actual debate teórico, ideológico y político sobre las identidades étnicas, nacionales y cosmopolitas en el mundo entero. Identidad se ha definido con frecuencia en términos 
de la mismidad, de lo que es igual a sí mismo. Es una visión egocéntrica y excluyente, muy difundida en el pensamiento moderno. Mediante esta abstracción se separa el objeto del entorno, de sus múltiples contextos de sentido, para definirlo en su singularidad. La alteridad es entonces vista como un no-yo, como lo absolutamente ajeno, externo, o como un referente de contraste u oposición respecto al yo.

Este binarismo entre ego y alter impide ver que el ser es resultado de una compleja interacción entre ambos. No se puede ser sin el otro. De allí la necesidad de repensar la identidad como un fenómeno social, resultado de las relaciones del ser consigo mismo y con otros. Puede imaginarse como una lente que conjuga haces de luz de las relaciones internas del sujeto, con las que éste mantiene con otros sujetos, con la alteridad en un sentido más amplio. El punto es, pues, que el problema de la identidad no puede entenderse a cabalidad sin el reconocimiento pleno de la alteridad como un factor constitutivo. El otro precede al yo, lo alimenta e instruye, y lo acompaña toda la vida. Se debe entonces reconocer que la función del otro en la construcción identitaria no se reduce a la oposición y el contraste, aunque pueda ser ésta una de sus funciones primarias.

En este ensayo busco avanzar hacia un entendimiento del fenómeno de la identidad social, indagando en las ideas del filósofo ruso Mijaíl Bajtín. Se plantea la identidad del sujeto como un fenómeno dialógico, en el que el otro es parte constitutiva del ser. La identidad del sujeto se forma y transforma en un continuo diálogo entre el sí mismo y el otro.

\section{La alteridad bajtiniana}

Bajtín examina la intersubjetividad desde una perspectiva fenomenológica que parte de la concreta relación yo-otro, ${ }^{1} \mathrm{de}$

\footnotetext{
${ }^{1}$ En la perspectiva que aquí se propone las categorías yo y otro son abstrac-
} 
este binomio fundante de su filosofía del lenguaje y de sus teorías ética y estética. De entrada, el énfasis en el sujeto como un ente social pone en cuestión el concepto mismo de identidad, al introducir la categoría de la alteridad como parte constituyente del yo, como su antecedente obligado y referente necesario. Al sujeto se le concibe más allá del eje egocéntrico, para ubicarlo en la red de relaciones dialógicas que establece consigo mismo y con la alteridad (en realidad, con una multiplicidad de otros). El yo no puede comprenderse íntegramente sin la presencia del otro. La identidad pierde así su eje egocéntrico y monológico; se vuelve heteroglósica. Identidad y alteridad se entienden entonces como conceptos interdependientes, complementarios, de una naturaleza relacional y relativa. $^{2}$

En Bajtín, esa relación entre sujetos tiene como marco global al dialogismo, principio filosófico central de su concepción del lenguaje y de la vida social en su conjunto. En la obra del filósofo, los significados del dialogismo son diversos, pero un punto de partida para su comprensión es su etimología, que refiere a la interacción de dos o más logos, cada uno con sus propios valores, voliciones y posicionamientos. El enunciado, el discurso, la heteroglosia, y en general su concepción global

ciones que en sus aplicaciones concretas se desdoblan, son relativas a las interacciones en cuestión, pudiendo comprender variantes de número y género. Por ejemplo, yo puede referir a un nosotros (inclusivo o exclusivo, femenino, masculino, neutro), mientras que otro puede representar a más de un otro a la vez, y variar dependiendo de la situación de que se trate (véase en particular la discusión acerca del tercero como una entidad participante del acto dialógico en Bajtín 1997, y en Malcuzynski 1990, 91).

${ }^{2}$ El dialogismo va mucho más allá de aquella otra visión, frecuente en el discurso antropológico, donde la alteridad es planteada como un elemento de oposición o contraste respecto a la identidad del sujeto. Vista así la identidad étnica, sólo las relaciones interétnicas contrastantes son tomadas en cuenta, dejando de lado otros niveles de relación entre los grupos interactuantes, otros ambientes y entidades participantes, incluyendo aquí las entidades metafísicas. Pensemos en la identidad de los pueblos indígenas americanos fundada en su relación con la Madre Tierra, por ejemplo. 
de la comunicación humana, derivan todos del principio dialógico, de la fundante relación yo-otro.

[...] recordemos que una teoría bajtiniana del discurso afirma que no sólo se trata de lo que acontece "al interior" de nuestra propia conciencia, sino en la frontera de la conciencia de otro sujeto cabal, completo, precisamente en el umbral. Para Bajtín, el más alto grado de socialidad estriba en el hecho de que cada experiencia interna, cada sujeto, termina por toparse con otro. Toda la "ontología del yo" en el sentido bajtiniano se dialogiza, en primera instancia, en esta frontera, y no puede realizarse más que en este lugar de encuentro lleno de tensiones. El sujeto siempre es el producto de su interacción con otros sujetos (véase supra, Malcuzynski, 22).

En esta perspectiva, la comunicación humana como acontece en la vida real no es un mero intercambio de mensajes basado en un código compartido y en un consenso de sentido, sino que, por el contrario, se trata siempre de una tensión vital entre logos fundamentalmente distintos, cada uno con su propia posición axiológica respecto al mensaje, a su objeto, al código, al emisor, así como a los contextos de interacción. El sentido de un enunciado, nos dice el filósofo, incluye la respuesta del receptor y no se realiza tomando las palabras mecánicamente, como si fuesen entradas de diccionario, colocadas una tras otra de acuerdo con reglas sintácticas, sino como elementos cargados de valoraciones sociales, puestas en juego en el proceso de la comunicación interdiscursiva.

Bajtín señala cómo desde la temprana adquisición del lenguaje y a lo largo de la vida, el hombre se inicia como un ser social y se desarrolla como tal construyendo su individualidad a partir del otro, de las acciones y del discurso del otro, para continuar con éste una íntima y compleja relación. "La conciencia del hombre despierta envuelta en la conciencia ajena" (1982, 360), el sujeto social se forma discursivamente, en el 
proceso comunicativo de yo con el otro, es decir que el discurso propio se construye en relación con el discurso ajeno, en el proceso de una íntima y constante interacción. ${ }^{3}$ Las respectivas identidades se construyen en el proceso de la comunicación interdiscursiva. Así pues, en Bajtín el ser presenta un carácter intrínsecamente dialógico, "ser es ser para otro y a través del otro para mí” (2000, 161-163). ${ }^{4}$

El dialogismo lleva a repensar la comunicación humana. Bajtín dice que nunca está dicha la última palabra, la palabra enunciada se lanza esperando una respuesta, será siempre un enunciado abierto al tiempo, que podrá tener una respuesta en el futuro, una resurrección en el gran tiempo. El sujeto es una unidad abierta al tiempo, es un participante de la vida social, con capacidad de reacción y creación propias frente a lo planteado por las circunstancias concretas. Éste es un planteamiento contrario al de teorías sistémicas donde el sujeto se encuentra definido por las reglas y relaciones estructurales de un sistema cerrado.

Es imposible que uno viva sabiéndose concluido a sí mismo y al acontecimiento; para vivir, es necesario ser inconcluso, abierto a sus posibilidades (al menos, así es en todos los instantes esenciales de la vida); valorativamente, hay que ir de-

${ }^{3}$ Incluso en el caso de relaciones altamente conflictivas, la figura y el discurso del otro no tienen como única función el ser negados por el yo, aunque la percepción subjetiva sea ésta, pues los nexos de relación son complejos y de distintos órdenes. El enemigo influye poderosamente en la conducta de su adversario, y sería una simplificación pretender que la relación se reduce al contraste, la oposición, o el rechazo y la descalificación. Los valores representados por la otredad enemiga pueden, como un efecto de reflejo, ser asumidos positivamente por el otro, por ejemplo.

${ }^{4}$ Es interesante en este sentido la perspectiva dialógica del multiculturalismo de Taylor: "Las personas, por sí mismas, no adquieren los lenguajes necesarios para su autodefinición. Antes bien, entramos en contacto con ellos por la interacción con otros que son importantes para nosotros: lo que George Herbert Mead llamó los 'otros significantes'. La génesis de la mente humana no es, en este sentido, monológica (no es algo que cada quien logra por sí mismo), sino dialógica" (2001, 53). 
lante de sí mismo y no coincidir totalmente con aquello de lo que dispone uno realmente (Bajtín 1982, 20).

La vida social es un espacio de relatividad, donde el sentido, los valores y los referentes cambian, dependiendo de la situación existencial concreta. La ética en Bajtín parte de una fenomenología del ser, de la responsabilidad —en su sentido de una respuesta - del sujeto ante los acontecimientos de la vida. La ética no se reduce, entonces, a un conjunto de normas éticas, sino más bien es la manera como el sujeto se relaciona con esas normas en el proceso de la vida real (1997).

Esta dinámica de la vida social y del sujeto implica movimiento y cambio continuos, pero, por otro lado, todo ello ocurre por vías y espacios de sentido preestablecidos, "ya habitados". Al igual que en el lenguaje, la sociedad tiene sus reglas de operación, de funcionamiento, sus tradiciones, sus estabilidades de significado, que son resultados históricos de las relaciones sociales, de la convención humana. Así, la estabilidad es resultado de la sedimentación de la experiencia de la vida en sociedad, y en ese sentido deben entenderse los conceptos de sistema y estructura como conceptos abstractos que aluden a esas regularidades, como lo es el sistema de la lengua respecto al habla, o teoría respecto de la praxis.

Otro concepto de suma importancia para el tema de la identidad es el de extraposición, que Bajtín desarrolló en su teoría literaria como un elemento fundamental de la creación estética. Éste consiste en la capacidad del autor de una obra literaria de abandonar momentáneamente su propio eje axiológico y trasladarse al lugar del otro — es decir, al de los personajes de su obra, y observarlo internamente, en un movimiento empático- - Luego, el autor vuelve a su propio lugar, retomando su mirada externa, exotópica, la cual le permite ahora observar desde una posición de frontera, por encima de los personajes, y completarlos mediante un excedente de visión. En ese doble 
movimiento exotópico es posible para el autor abarcar la vida, el carácter, la identidad de sus personajes, ${ }^{5}$ y con ello, producir la vivencia estética en el lector.

Pero la extraposición no es algo que logre sólo un buen escritor, sino una habilidad que practica cualquier sujeto en el proceso de construcción de su identidad. Me refiero aquí a un fenómeno de estetización de las relaciones sociales. Valoramos nuestro propio ser desde el otro, buscamos conocernos a través del otro, vemos nuestra exterioridad con los ojos del otro, orientamos nuestra conducta en relación con el otro, construimos nuestro discurso propio en referencia al discurso ajeno, entrelazado con éste, en respuesta a él y en anticipación a sus futuras respuestas. En el mismo sentido, debido a nuestra situación de exterioridad respecto al otro, poseemos una parte de éste que lo completa, un "excedente de visión", que es accesible sólo a nosotros en virtud de nuestra ubicación relativa respecto de aquel. Es así, con la ayuda del otro, como el yo construye su identidad. ${ }^{6}$ De allí que encontremos en Bajtín una arquitectónica en la identidad del sujeto, consistente en una triada de relaciones básicas que son: yo-para-mí, yo-paraotro, y otro-para-mí. ${ }^{7}$ Es la arquitectónica resultante de las relaciones del yo consigo mismo (su percepción interna, su autoimagen), y las relaciones de ese yo con el otro. Así pues, estamos frente a una identidad construida y sobredeterminada por la alteridad.

Este complejo de relaciones dialógicas examinadas desde la fenomenología pueden ampliarse hacia ámbitos sociológicos y

${ }^{5}$ La obra literaria es justamente un ejemplo de cómo la identidad —en este caso de los personajes de la obra- se construye en el proceso estético de la interacción del autor y el personaje, en el incesante juego de percepciones interna y externa, en fin, en la fundante relación de yo con el otro.

${ }^{6}$ Esto no significa que las relaciones entre uno y otro sean equitativas o armónicas, ya que éstas se encuentran marcadas por relaciones de poder, que hacen de la identidad un espacio de dominación y alienación.

${ }^{7}$ Véase el tratamiento de Bubnova (1994) de esta arquitectónica en la ética de Bajtín. 
culturales mayores. ${ }^{8}$ De hecho, en sus consideraciones sobre la extraposición, Bajtín la plantea como el instrumento más poderoso para la comprensión de la cultura, proyectando así sus observaciones del plano intersubjetivo al de las relaciones interculturales y al ámbito de los estudios culturales. Y es que así como ocurre en el plano del sujeto, tampoco la cultura puede completar la imagen de sí misma desde su interioridad, pues necesita del referente que le proporciona la alteridad, necesita la mirada de las otras culturas para enriquecer su propio entendimiento. De allí que eso a lo que llamamos identidad debe entenderse como un fenómeno de frontera, como algo que ocurre en el umbral de intersección entre yo y el otro, en el encuentro exotópico con la alteridad.

El filósofo propone una metodología de investigación para las humanidades en la que se practique una empatía, una "puesta en el lugar del otro", a fin de acercarse a la percepción interna de la cultura, pero sin excluir la participación activa de la cultura del investigador, su visión externa, exotópica. Al igual que ocurre en la creación estética, estos dos movimientos se complementan para dar una visión integral de la cultura. Bajtín plantea que como resultado de este viaje exotópico, el artista, o en nuestro caso el investigador, nunca regresa al mismo lugar de partida, sino que se coloca en un lugar de fronte$r a$, desde el cual ejerce su mirada y realiza su obra. Ese particular lugar de frontera en donde se ubica el autor determinará en gran medida el carácter dialógico de su producción, y, en el caso del artista, la calidad estética de su obra.

\footnotetext{
${ }^{8}$ Véase el ensayo de Ponzio sobre la alteridad en Bajtín y el problema de la búsqueda de identidad en Europa. "The other imposes his irreducible alterity upon the self $[\ldots]$ it is the self that constructs itself and that must make a space already belonging to others. [...] A social group is recognized as such through a complex process of differentiation with respect to that which is other. Before being the result of a choice, decision, or conscious act, group identity is the passively experienced result of relations with other groups, it is a determination that ensues from others, from their behaviours and orientations" (1990, 222 ss.).
} 
La extraposición es, pues, un recurso metodológico fundamental para el entendimiento de la cultura. ${ }^{9}$ En el caso del antropólogo, éste ha de practicar, desde los parámetros de su propia disciplina, un viaje exotópico constante entre su cultura, entre su visión del mundo y el mundo del otro, una suerte de diálogo intercultural, en el que los sujetos investigados tengan la posibilidad de expresión propia, pero también la capacidad para replicar al discurso antropológico.

\section{Conclusiones}

Si queremos comprender la íntima conexión que existe entre la identidad y el reconocimiento tendremos que tomar en cuenta un rasgo decisivo de la condición humana que se ha vuelto casi invisible por la tendencia abrumadoramente monológica de la corriente principal de la filosofía moderna. Este rasgo decisivo de la vida humana es su carácter fundamentalmente dialógico.

[...] El que yo descubra mi propia identidad no significa que yo la haya elaborado en el aislamiento, sino que la he negociado por medio del diálogo, en parte abierto, en parte interno, con los demás. Por ello, el desarrollo de un ideal de identidad que se genera internamente atribuye una nueva importancia al reconocimiento. Mi propia identidad depende, en forma crucial, de mis relaciones dialógicas con los demás.

Charles TAylor $(2001,52,55)$

La alteridad bajtiniana es un principio filosófico de extrema importancia para repensar la identidad. El dialogismo, junto

\footnotetext{
${ }^{9}$ Lévi-Strauss reconoce, en su introducción a la obra de Mauss, la necesidad de esta visión exotópica en la comprensión de la cultura ajena: "Para comprender convenientemente un hecho social, hay que captarlo totalmente, es decir, desde fuera, como si se tratara de una cosa, pero como una cosa de la que, sin embargo, forma parte integrante la captación subjetiva (consciente o inconsciente) que realizaríamos si, siendo inevitablemente hombres, viviéramos el hecho como el indígena, en lugar de observarlo como el etnógrafo" (citado en Augé 1996, 31).
} 
con otros conceptos teóricos derivados, son claves bajtinianas para la comprensión de la cultura y en particular la identidad del sujeto, entendida esta como un fenómeno social, resultado del complejo de relaciones del yo (o en su caso el nosotros) consigo mismo y con el otro (ellos). Ese carácter sociológico de la identidad hace de ésta un proceso de relaciones ideológicas, políticas e históricas, un espacio de tensión de intereses, de posiciones, de negociación de sentido. La identidad es un campo de lucha, una agonística en la que se disputan los valores del yo frente a sí mismo y frente al otro. Taylor nos dice que "la formación de la identidad y del yo tiene lugar en un diálogo sostenido y en pugna con los otros significantes" (2001, 59). Pero a la vez la identidad puede concebirse como una particular estetización del ser, en la medida en que se trata de una puesta en juego de al menos dos visiones, dos percepciones, la propia y la ajena. ${ }^{10}$ La identidad social, al igual que la creación estética, son fenómenos de frontera, ocurridos en el umbral entre yo y el otro.

Para la antropología, disciplina especializada en la alteridad cultural, resulta de especial relevancia la perspectiva teórica de una identidad social no cerrada en sí misma, sino una que por el contrario involucre de lleno a la alteridad. La identidad debe entenderse como un fenómeno de naturaleza sociológica y, por lo mismo, de un carácter intrínsecamente relacional y relativo, resultado del complejo de relaciones tanto del yo consigo mismo, como de éste con el otro en sus múltiples y cambiantes planos de interacción. ${ }^{11}$

\footnotetext{
10 "Cuando existe un solo participante único y total, no hay lugar para un acontecer estético; la conciencia absoluta que no dispone de nada que le fuese extrapuesto, que no cuenta con nada que la limite desde afuera, no puede ser estetizada [...]. Un acontecer estético puede darse únicamente cuando hay dos participantes, presupone la existencia de dos conciencias que no coinciden" (Bajtín 1982, 28).

11 Augé (1996) reconoce explícitamente el carácter relacional y relativo de la identidad al vincularla con el concepto de alteridad, en un sentido similar al aquí propuesto. "Detrás de la certeza cerrada del mundo occidental, Freud des-
} 
Esta perspectiva es necesaria no sólo para una justa comprensión del fenómeno identitario, sino porque el mismo plantea una metodología de investigación que exige una reflexión sobre la presencia y la participación del antropólogo como una alteridad más, participante en la construcción de la imagen de identidad de los sujetos de estudio. ${ }^{12} \mathrm{El}$ investigador debe ser consciente de su lugar autoral, del poder inherente en su ejercicio discursivo, así como de su relación exotópica respecto a la cultura y los sujetos estudiados; en resumidas cuentas, de las relaciones interculturales que se accionan a través de su particular actividad cognitiva. De hecho, observamos hoy en día propuestas novedosas en este campo, tanto en el plano general de la disciplina como en la investigación etnográfica, inspiradas en el pensamiento bajtiniano. ${ }^{13}$

La perspectiva dialógica propuesta nos permite superar el paradigma barthiano de la identidad social entendida como un fenómeno de contraste, en el que se privilegia la oposición respecto a la alteridad como la relación definitoria de la identidad. ${ }^{14}$ Ciertamente, un rasgo sobresaliente de la construcción

cubre un mundo, el otro en el sí mismo, se podría decir que las aventuras y los avatares del ego remiten a su origen plural, al complejo de Edipo y a la escena primitiva. El otro próximo soy yo mismo [...]. Si nos atenemos al psicoanálisis, observaremos que el movimiento mediante el que descubre al otro en el sí mismo (la pluralidad en lo singular) se prolonga o se cumple en el descubrimiento etnológico del mismo en el otro" $(1996,48)$. De sus estudios etnológicos en África, Augé deriva la propuesta de una alteridad íntima en los nativos, de acuerdo con la cual, "el individuo es, por definición, compuesto. La relación reside en el corazón de la identidad. La alteridad y la identidad no se conciben la una sin la otra..." $(1996,102)$.

12 Debe advertirse, sin embargo, que este reconocimiento, ampliamente explorado por la etnografía posmoderna, no debe conducir a una suerte de reificación del antropólogo como autor del texto etnográfico.

${ }^{13}$ Véanse en especial las propuestas de etnografía posmoderna recogidas en la seminal antología de Clifford y Marcus (1986), y para el campo las humanidades y ciencias sociales en general, Barsky y Holquist (1990), Eriksen (1993), Geertz (1989), Taylor (2001), Tedlock y Mannheim (1995), Faraco (2004).

${ }^{14}$ Me refiero a la teoría de la identidad étnica de Barth (1976). Este autor señala la frontera como espacio de construcción de la identidad social, pero su propuesta se limita a la consideración de las relaciones interétnicas contrastantes. En este sen- 
identitaria es el distinguirse del otro, el marcar las diferencias, y eso es normal, particularmente cuando existen relaciones conflictivas y de dominación entre un grupo y otro. Pero la construcción identitaria no se agota en un solo tipo de relación, ni en un solo nivel de realidad social; siempre habrá otras relaciones en otros planos, así como otros grupos no antagónicos, otros aliados, otras entidades participantes; en fin, en el análisis dialógico es indispensable examinar el complejo de interacciones en situaciones concretas, considerando no sólo las relaciones empíricas de un grupo con otro, sino el complejo de relaciones, incluyendo las de los humanos con las divinidades y los órdenes morales y éticos puestos en juego.

Observar dialógicamente la relación entre nosotros y ellos en la construcción identitaria permite examinar de lleno las relaciones de dominación, el peso excesivo o totalitario que pueden ejercer unos sobre otros —el desplazamiento de la cultura propia por la ajena, por ejemplo-, y permite a su vez comprender el reclamo de reconocimiento de una diversidad de movimientos sociales contemporáneos (feministas, étnicos, nacionalistas, altermundistas, etc.). También las nuevas exclusiones, producto de los recientes conflictos y a su modo esperable resultado de las exclusiones pasadas, resultados que pretenden invertir el balance cultural y en potencia podrían llevar a nuestros países a una balcanización, deberían tomarse en cuenta. Pero la exotopía bajtiniana es un principio valioso no sólo para la investigación humanista, sino para una reflexión de las culturas mismas, las cuales pueden llegar a concebirse más allá de la exclusión, como partícipes de un universo de relaciones interculturales al interior del cual han de construir

tido, es interesante la postura de Giménez (1996) respecto al carácter intersubjetivo, relacional y "pluridimensional" de la identidad social. Un caso etnográfico relevante lo presenta López García (2004) en cuanto a "la volubilidad respecto a la autoidentificación étnica" en Guatemala, ejemplificada en un "deseo de experimentar la diferencia": mayas que "prueban" (adoptan) temporalmente elementos culturales ajenos, mientras por otro lado, ladinos que "quieren ser mayas". 
su identidad. Considero esta propuesta teórica de especial valor para movimientos de reivindicación cultural que, como en el caso de los indígenas americanos, buscan el pleno reconocimiento de su existencia y de su derecho a una vida digna y próspera.

Para aquellas culturas que sufren del dominio, la destrucción y la exclusión, estos planteamientos pueden conducir hacia una revaloración de lo propio y a un replanteamiento de los términos de la relación con la alteridad dominante, y en este sentido a una liberación del nosotros (una autoafirmación) que no se fundamente, como en el pasado, en la anulación de los demás, sino busque la equidad en las relaciones interculturales. La demanda de reconocimiento de la voz propia no debe llevar a un monólogo que silencie al otro, sino al establecimiento de un verdadero diálogo democrático. ${ }^{15}$

\section{Bibliografía}

Augé, Marc, El sentido de los otros. Actualidad de la antropología, Barcelona, Paidós, 1996.

Bajtín, Mijaíl, Estética de la creación verbal, México, Siglo XXI Editores, 1982.

—, Hacia una filosofía del acto ético. De los borradores y otros escritos, Barcelona, Anthropos Editorial, 1997.

Bajtín, Mijaíl, Yo también soy. Fragmentos sobre el otro, México, Editorial Taurus, 2000.

BARSKY, Robert, y Michael Holquist (editores), Bakhtin and Otherness, Discours social/Social Discourse, vol. III, núms. 1 y 2, 1990.

15 "El reconocimiento igualitario no sólo es el modo pertinente a una sociedad democrática sana... La proyección sobre otro de una imagen inferior o humillante puede en realidad deformar y oprimir hasta el grado en que esa imagen sea internalizada. No sólo el feminismo contemporáneo sino también las relaciones raciales y las discusiones del multiculturalismo se orientan por la premisa de que no dar este reconocimiento puede constituir una forma de opresión" (Taylor 2001, 58-59). 
BARTH, Fredrik (editor), Los grupos étnicos y sus fronteras, México, Fondo de Cultura Económica, 1976.

Bonfil Batalla, Guillermo, "La teoría del control cultural en el estudio de los procesos étnicos", Acta Sociológica. Nación e identidad, México, unam, núm. 18, 1996, pp. 1-54.

Bubnova, Tatiana, "El lugar de la filosofía del acto ético en la filosofía del lenguaje de Bajtín", en Gimate-Welsh (editor), Escritos. Semiótica de la cultura, Oaxaca, México, Universidad Autónoma Benito Juárez, 1994, pp. 173-184.

Clifford, James, y George Marcus (editores), Writing Culture. The Poetics and Politics of Ethnography, California, University of California Press, 1986.

ERIKSEN, Thomas, Ethnicity and Nationalism. Anthropological Perspectives, Londres y Boulder, Colorado, Pluto Press, 1993.

FAnon, Frantz, Piel negra máscaras blancas, Buenos Aires, Editorias Abraxas, 1973.

FARACO, Carlos (editor), Proceedings of the Eleventh International Bakhtin Conference, Curitiba, Brasil, Universidad Federal de Paraná, 2004.

Geertz, Clifford, El antropólogo como autor, Barcelona, Ediciones Paidós, 1989.

GimÉNEz, Gilberto, "La identidad social o el retorno del sujeto en sociología", en Leticia Méndez (coord.), Identidad: análisis y teoría, simbolismo, sociedades complejas, nacionalismo y etnicidad. III Coloquio Paul Kirchhoff, México, unam, 1996, pp. 1124.

MalcuZYNSKI, Pierrette, "Mikhail Bakhtin and the Sociocritical Practice", en R. Barsky y M. Holquist (editores invitados), Discours social/Social Discourse. Bakhtin and Otherness, vol. III, núms. 1 y 2, 1990, pp. 83-98.

—, "Yo no es un O/otro", Acta Poetica, 27:1 (2006), 17-40.

Petrich, Perla (coordinadora), Identités: positionnements des groupes indiens en Amérique Latine, Les Cahiers ALHIM (10), Paris, Universidad de Paris 8, 2004.

PonzIO, Augusto, "Bakhtinian Alterity and the Search for Identity in Europe Today", en R. Barsky y M. Holquist (editores invita- 
dos), Bakhtin and Otherness, Discours social/Social Discourse, vol. III, núms. 1 y 2, 1990, pp. 217-228.

TAYLOR, Charles, El multiculturalismo y "La política del reconocimiento”, México, Fondo de Cultura Económica, 2001.

Tedlock, Dennis, y Bruce Mannheim, The Dialogic Emergence of Culture, Urbana y Chicago, University of Ilinois Press, 1995.

Voloshinov, Valentín, El marxismo y la filosofía del lenguaje, Madrid, Alianza Editorial, 1992.

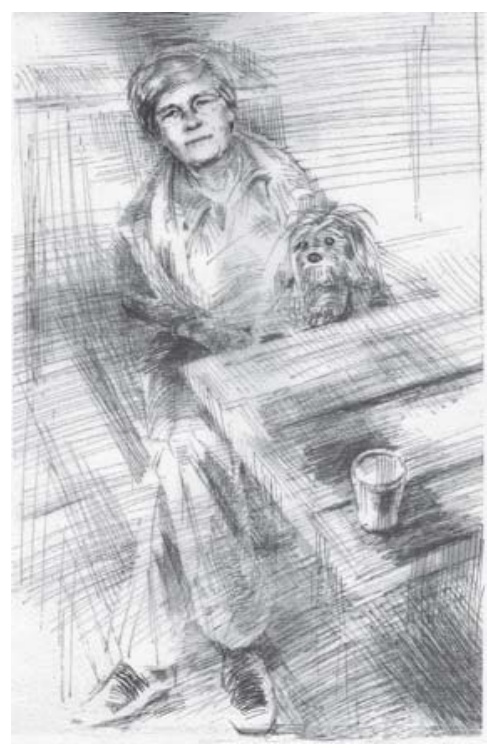


